\title{
ARE YOU NOW OR HAVE YOU EVER BEEN A SOCIOLOGIST?
}

\author{
BARRY KRISBERG, Ph.D.*
}

\section{INTRODUCTION}

At the recent National Crime Summit, Attorney General Dick Thornburgh declared, "We are not here to search for the root causes of crime or to discuss sociological theory." He went on to explain that "debate over the root causes of crime will go on for decades, but the carnage in our mean streets must be stopped now." The topic of crime causation was hardly ever mentioned over the next two days of the Crime Summit.

Judging from the sentiments expressed by the Attorney General, and echoed by President George Bush, the policy relevance of recent advances in delinquency theory and research is minimal, at best. The situation was not always so. Nearly twenty-five years ago, another American President, Lyndon Baines Johnson, launched a major national war on crime in which research and delinquency theory were important elements. Sociological theories developed during the early 1960 s played a prominent role in directing federal anticrime programs and provided the intellectual framework for a national campaign to reduce poverty.

Explaining how delinquency theory and research were banished from the national policy agenda is one goal of this essay. My second objective is to suggest how delinquency research would alter our current response to youth crime. In particular, the theoretical and empirical contributions contained in this special issue will be examined in light of their potential utility in the prevention and control of youth crime. Finally, I will offer some modest suggestions to researchers who harbor continued hope that the scientific enterprise may yet inform social policy.

* President, National Council on Crime and Delinquency, 685 Market Street, Suite 620, San Francisco, CA 94105. 


\section{Are You Now Or Have You Ever Been A Sociologist?}

In the 1960 s and early 1970 s, sociological theories of delinquency greatly influenced policy design and development. The seminal work of Cloward and Ohlin' ${ }^{1}$ became the blueprint for delinquency prevention programs funded through President John F. Kennedy's Office of Juvenile Delinquency. President Johnson's Commission on Law Enforcement and the Administration of Justice ${ }^{2}$ urged the nation to direct the fight against crime towards combatting poverty, school failure, urban decay, and unemployment. Social Learning Theory shaped many innovative responses to youthful offenders, ${ }^{3}$ while Labeling Theory's enormous popularity supported policies of decriminalization, diversion and deinstitutionalization for juvenile offenders. ${ }^{4}$

During the 1970s, however, both progressive and conservative critics increasingly questioned the prestige and policy impact of sociological approaches to crime (as well as other social problems). Two extremely influential conservative authors during this period were James $Q$. Wilson and Ernst Van den Haag. ${ }^{5}$

Wilson criticized the search for the root causes of crime:

I have yet to see a root cause or to encounter a government program that has successfully attacked it, at least with respect to those social problems that arise out of human volition rather then technological malfunction. ${ }^{6}$

Both Wilson and Van den Haag advocated a rudimentary economic model to replace existing sociological theories of crime. Their paradigm suggested that effective crime control can be maximized if the "costs" of crime (i.e. apprehension and punishment) can be made to outweigh the benefits of criminal behavior. Criminals are presumed to make rational calculations as a prelude to engaging in criminal behavior. The key factor in Wilson's and Van den Haag's criminological calculus is the extent to which society can escalate the expected penalties associated with criminal activity. Their theories, however, fail to comprehend adequately the potential for individuals to engage in pro-social behavior due to positive inducements.

Although a number of criminologists have ably criticized the ra-

\footnotetext{
I R. Cloward \& L. Ohlin, Delinguency and Opportunity (1960).

2 N. Katzenbach, The Challenge of Crime in A Free Society (1967).

3 L. Empey \& S. Lubeck, The Silveri.ake Experiment (1971).

4 Lemert, Diversion in Juvenile Justice: What Hath Been Wrought, $18 \mathrm{~J}$. Res. ON CrIme \& DELINQ. 34 (1981).

5 See especially J. Wilson, Thinkinc About Crime (1975); E. Van den HaAg, PunishING Criminals (1975). An excellent progressive critique of traditional sociological theories was I. TAylor, P. Walton \& J. Young, The New Criminology (1973).

6 J. Wilson, Thinking About Crime, supra note 5 , at xv.
} 
tional calculus paradigm advocated by Wilson and Van den Haag,? the public, increasingly frustrated with the crime problem, embraced their views. More important, in the 1970 s, politicians discovered that "law and order" was an effective jingo for a multitude of conflicts in American society.

The perspective of Wilson and Van den Haag fit with a reemergence of puritanism as a dominant force in American political and social discourse. In this formulation, evil is a virtually inevitable character flaw of certain individuals. Social and economic forces are assumed to have little impact on deviant behavior. If criminals are predestined, then government funded prevention or intervention programs are largely irrelevant. Differential crime rates among social classes, racial groups, or different communities need not be examined. Instead, individual accountability for misdeeds is the centerpiece of crime control policy. As such, punishment becomes the primary societal response to offenders, and religious conversion is the only acceptable rehabilitation program.

Concurrent with the political influence of Wilson and Van den Haag, a number of equally influential researchers challenged the evidence that rehabilitation programs were effective in reducing recidivism. Most notably, the work of Robert Martinson was taken as a blanket indictment of rehabilitation programs, although Martinson later recanted his position. ${ }^{8}$ Others made bold claims for the crime control value of traditional incarceration. ${ }^{9}$ These discouraging evaluations of correctional interventions combined with the growing prominence of economists claiming to demonstrate the social utility of deterrence and incapacitation policies helped erode the prestige of sociological approaches to crime and delinquency. ${ }^{10}$

Federal research priorities re-enforced the demise of sociological theories. Funding for sociological studies of social problems waned, particularly during the Reagan era. Instead, the concept of "criminal careers" dominated crime research, and researchers sought to determine the magnitude of crime control accomplished by taking these hardened recidivists "out-of-circulation." Until quite recently, financial support to study the etiology of delinquency was difficult to find from either governmental or private sources.

7 See, e.g., E. Currie, Confronting Crime (1985).

8 Martinson, What Works-Questions and Answers About Prison Reform, 36 PUB. INT. 22 (1974); Martinson, New Finding, New Views: A Note of Caution Regarding Sentencing Reform, 7 HoFstra L. REv. 242 (1979).

9 See, e.g., C. Murray \& L. Cox, Beyond Probation (1979).

10 See Deterrence and Incapacitation: Estimating the Effects of Criminal Sanctions on Crime Rates (A. Blumstein, J. Cohen \& D. Nagin eds. 1978). 
Meanwhile, on the policy front, the nation pursued an unprecedented expansion of imprisonment as well as other forms of criminal justice supervision. Between 1980 and 1988, the prison population grew by $90 \%$ and jails grew by $110 \%$. In addition, the number of adult probationers increased by $111 \%$. This massive increase in the correctional system occurred even though the crime rate remained virtually unchanged. ${ }^{11}$ Juvenile incarceration rates grew by $43 \%$, but juvenile arrest rates for Part 1 Crimes actually declined by $18 \%$ during the decade of the $1980 \mathrm{~s}^{12}$

The costs, both direct and indirect, of such expansion were significant. The States and the Federal government invested tens of billions of dollars in new prison and jail construction. Direct government spending on corrections increased by $59 \%$ in real dollars, and the number of corrections workers grew by $71 \% .^{13}$ This increased spending for incarceration strained budgets and left few resources for preventive or "front-end" programming. ${ }^{14}$

The "get tough" rhetoric remains politically potent today. The effective television commercial about a furloughed Massachusetts convict named Willie Horton vividly demonstrates this potency. The ability to label Presidential candidates as "soft on crime" has had a chilling effect on the national debate on crime prevention policies.

Finally, the conservative domestic agenda has also adversely affected the advancement of sociological theories of crime. In the $1980 \mathrm{~s}$, principles of laissez-faire and the silent corrective force of the marketplace formed the intellectual foundation of this conservative domestic agenda. ${ }^{15}$ Adherents attacked the capacity of government programs to remedy most social ills and viewed most governmental programs as counterproductive.

In this intellectual and political milieu, the search for the causes of delinquency was discouraged. That a few intrepid researchers continued their studies in this environment is laudable. The pendulum, however, is beginning to swing back in the other direction. The need for sociological theories to inform crime and delinquency policy is once again becoming apparent.

11 Austin, America's Growing Correctional-Industrial Complex, NCCD Focus 1 (Dec. 1990).

12 B. Krisberg, R. DeComo, N. Herrera, M. Steketee \& S. Roberts, Juveniles Taken Into Custody Research Program: FY 1990 Annual Report (1991) (prepared for National Council on Crime and Delinquency; available through author).

13 Austin, supra note 11 , at 4-5.

14 Krisberg, California Juvenile Justice in Turmoil, in California Policy Choices: VolUME Four 119 (J. Kirlin \& D. Winkler eds. 1988).

15 See, e.g., C. Murray, Losing Ground: American Social Policy 1950-1980 (1984). 
The expensive failure of incarceration as a dominant domestic strategy has rekindled interest in discovering the root causes of crime (the Attorney General notwithstanding). In addition, many governors and state legislatures have acknowledged the need to return the focus to children and family programs. This renewed interest in at-risk children appears to transcend political party lines. For example, California's conservative Governor Pete Wilson emphasized preventive strategies in his inaugural address. Several national leaders echo this concern:

Former Illinois Governor James Thompson stated, "Failing to deal promptly with children's plight will not only drive up the cost of government significantly as we pay the price of ignorance, poverty, mental illness, disability, crime and death. And it will scar our souls." Similarly, South Carolina Governor Carroll Campbell commented, "I'm going to recommend instead of more prisons to expend $\$ 4$ million to our youth services .... We either deal effectively with these kids now or deal ineffectively with them in our prisons." Kansas Governor Mike Haden agreed, "By investing early in the treatment of our young citizens we all stand to gain from their health and productive futures."16

Finally, William J. Wilson and Lisbeth Schorr have demonstrated that the pessimistic claims of the conservative critics of social programs are grossly overstated. ${ }^{17}$ The political support for a re-examination of crime causation is building.

Some federal research dollars are being invested in basic delinquency research. The papers contained in this volume represent the early harvest of research investments made by the Office of Juvenile Justice and Delinquency Prevention. The National Institute of Justice has launched a parallel effort in partnership with the John $\mathbf{D}$. and Catherine T. MacArthur Foundation. In the next section of this paper, I will briefly review the contributions of the OJJDP supported studies and their utility to reform juvenile crime control policies.

\section{Program of Research on the Causes and Correlates of Delinguency}

Three major research efforts were initiated in 1986. Each of these studies sought to rectify major gaps in the previous research literature. All three studies are longitudinal in design to permit examination of both changes in offending patterns and relationships of those dynamic patterns with causal or risk factors. OJJDP re-

16 NCCD Professional Council, What Kind of Future: Crime and Punishment in THE YEAR 2000 (1988) (prepared for the National Council on Crime and Delinquency; available through the author).

17 See W. Wilson, The Truly Disadvantaged (1987); see also L. Schorr, Within Our Grasp: Breaking the Cycle of Disadvantage (1988). 
quired that the research designs reflect an interdisciplinary team approach and that a broad range of social, psychological, behavioral and environmental factors be investigated. OJJDP further requested that the researchers construct a theoretical perspective to guide their selection of risk factors. Sampling plans covered communities with serious delinquency problems, and the research subjects included a sufficient number of high risk children and youth.

The studies summarized in this special issue cover extensive research efforts in Denver, Colorado; Pittsburgh, Pennsylvania; and Rochester, New York. Besides the longitudinal research designs, each of these studies relies on self-report measures of delinquency as well as extensive interviews with youths and their families. These multiple sources of data are important, as prior longitudinal research that relied exclusively on official police data was considered suspect due to the complex co-variance of law enforcement practices and actual delinquent behavior. ${ }^{18}$ Finally, the data collected at each site substantially overlaps, which permits the permits investigation of causal relationships across three diverse communities.

\section{A. THE DENVER YOUTH SURVEY}

Researchers at the University of Colorado, most notably Delbert Elliott and David Huizinga, have made major contributions to the evolution of delinquency theory and research. Their National Youth Survey remains the best source of data on the prevalence and incidence of delinquency and drug use among adolescents. ${ }^{19}$ Elliott and his colleagues have constructed an integrated perspective on delinquency that has already been subjected to extensive empirical verification and refinement. In this volume, Huizinga, Ebsensen, and Weiher extend their analyses to consider multiple pathways to delinquency.

The Denver Youth Study examines clusters of youths who fit into the categories of non-offenders, infrequent offenders, and frequent delinquents. The researchers are able to study transitions over time among these typologies in a child and a youth sample. Within a one year time frame, most youths stay within their existing typology. The most typical movement is to an adjacent grouping, and both escalation and de-escalation of offense frequency was observed.

18 See Bernard \& Ritti, The Philadelphia Birth Cohort and Selective Incapacitation, 28 J. Res. In Crime \& Deline. 33 (1991).

19 See D. Elliott, D. Huizinga \& S. Ageton, Explaining Delinquency and Drug USE (1985). 
The Denver Youth Study reports an array of correlates between these delinquent typologies and various background factors such as parental relationships, peer involvement, pro-social attitudes, and school participation. The researchers find multiple clustering of children and youths on each of their background variables. There are also complex associations of these clusters with both the frequency patterns and the changes in offending patterns. However, a key finding of the Denver Youth Study is that youngsters classified as delinquents, including the most highly delinquent, come from all major personal background types. In particular, there are significant numbers of youths from pro-social environments who hold generally conventional attitudes but who engage in delinquent behavior.

Huizinga et al. have begun an elementary mapping of some of the multiple pathways to delinquency. Future research findings will explore how changes in personal environments impact on transitions in delinquent behavior.

The concept of "multiple pathways" has obvious intuitive appeal. All but the most naive must sense that there cannot be a single causal process through which all offenders become delinquents. The concept of multiple pathways to delinquency should deter simplistic and often single factor approaches to the prevention and control of delinquency prevention. The delinquency field is constantly invaded with "visionaries" who see a single cure for chronic delinquency. The recent media hype over "Scared Straight" and "Tough Love" are but two examples of the quest for the magic cure to delinquency.

The existence of multiple pathways is quite consistent with the early theoretical and clinical approaches of the juvenile court. For example, the pioneering work of William Healy involved intensive case studies of thousands of delinquents. ${ }^{20}$ The juvenile court's philosophy has long rested on the premise of individualized diagnosis and treatment of wayward youths. Unfortunately, overwhelming caseloads, insufficient professional resources, and limited dispositional options severely inhibit the juvenile court's ability to successfully implement its philosophy with any degree of frequency.

One clear policy implication of the Denver Youth Study is that planners of delinquency prevention and treatment programs must avoid assembly-line solutions to handling delinquents. Without true individualization of treatment, most interventions will be extraordinarily inefficient and, perhaps, counterproductive. Similarly, 
programs must be small enough to permit staff to respond to the multiple pathways into and out of delinquency. To accomplish this objective would require uniform, comprehensive reform of the nation's juvenile court systems, where massive processing of youths remains the norm. The reality of multiple pathways to delinquency also argues for improved technologies for offender classification and placement.

The Denver Youth Study also illustrates the intellectual poverty of the "get tough" perspective on youth crime. At best, only a small subset of delinquents seem amenable to the political "scare tactics" of public officials. Given the diversity of personal environments and delinquent involvement, should we be really surprised that youths do not immediately respond when adults "send them messages" that misconduct will be severely punished?

\section{B. THE ROCHESTER YOUTH DEVELOPMENT STUDY}

The work of Thornberry and his colleagues is guided by a novel and highly appealing conceptual perspective, Interactional Theory. While noting that attachment to parents and school are important correlates of conformist behavior, Interactional Theory suggests that frequent delinquent behavior worsens ties between parents and children and lessens the child's commitment to school. These deteriorations in social bonds establish a behavioral trajectory towards increasing delinquency. ${ }^{21}$

The Rochester Youth Development Study attempts to elucidate the complex co-variation of delinquency and its correlates through a longitudinal design involving nearly 1000 seventh and eighth graders in the Rochester public schools. This study employs self-report delinquency measures and other questionnaire items similar to those used in the Denver research.

The Rochester Youth Development Study has many policy implications. Since delinquency itself serves to isolate the youngster from those positive social ties that might reduce future misconduct, program planners need to devote more attention to this estrangement process. Most directly, this means working with families and school officials to attempt to limit the damage that delinquent behavior may exert on these critical social attachments. Too often, delinquency prevention and control specialists define parents and school officials as "unworkable" and thus confine their interventions

21 Thornberry, Lizotte, Krohn, Farnworth \& Jang, Testing Interactional Theory: An Examination of The Reciprocal Causal Relationships Among Family School and Delinquency, $82 \mathrm{~J}$. Crim. L. \& Criminology 3, 31 (1991). 
to the delinquent youths themselves. This avoidance is understandable in many instances. Many delinquent youths have run away from chaotic and abusive home environments; others have been "thrown away" by parents who are unable to manage their child's behavior. Likewise, schools are often so overtaxed in meeting their minimum educational objectives that the extra effort to reintegrate disruptive students is seemingly beyond the resources of teachers and school officials.

Even worse, delinquency control programs often intentionally remove the youngster from the community for extensive periods of time. This removal strategy diminishes the ability of treatment staff to re-form family and school bonds. Only a handful of jurisdictions, such as Massachusetts, Missouri, and Utah, have completely reorganized their youth corrections systems around the central principle of community-based care of troubled youths. In these states, the number of juveniles in isolated, locked settings is minimal, and tremendous emphasis is placed on reintegration and aftercare services. Recent research on the Massachusetts system indicates very positive results in terms of reduced recidivism. ${ }^{22}$ Other states are gradually moving toward the community-based model, and the juveniles courts are increasingly recognizing the value of intensive homebased services such as the Homebuilders program. ${ }^{23}$

Not so long ago, notions such as "avoiding stigmatization," "normalization," and "the least restrict alternative" dominated delinquency control theories. These tenets of juvenile court jurisprudence led to a wide variety of diversionary and alternative treatment options. However, the conservative penal philosophy of the 1980s dismissed these concepts as misguided liberalism. ${ }^{24}$ The deterrence policies pushed by the "hard liners" further widened the gap between the delinquent and his/her community through isolation and punitive sanctions.

The Rochester Youth Development Study also points to the complex and multiple factors leading to the onset, escalation, and de-escalation of delinquent behavior. The authors state that "since delinquency appears imbedded in a rather complex causal network, there is no single, direct pathway to delinquency."25 Their conclu-

22 B. Krisberg, J. Austin \& P. Steele, Unlocking Juvenile Corrections (1991).

23 Homebuilders involves short-term, in-home family therapy. Therapists have a two-family caseload, remain on 24 hour call, and devote 8-10 hours a day to a family in crisis. See D. Steinhard \& E. Steele, Juvenile Justice Models for Califoria (1940).

24 Krisberg, Schwartz, Litsky \& Austin, The Watershed of Juvenile Justice Reform, 32 Crime \& Deline. 5 (1988).

25 Thornberry, supra note 21 , at 32. 
sion echoes the findings of Huizinga et al. The Rochester researchers urge policy makers to construct holistic programs that are comprehensive and which respond to multiple causal factors in one program package. Because Interactional Theory argues for interrelated causal factors, single dimensional interventions will not be effective. However, these interconnections can also be leveraged to multiply the impacts of specific delinquency prevention efforts.

Thornberry et al. suggest that family interventions should start relatively early in life, because family attachments become less related to non-delinquency as adolescents mature. Since predicting "pre-delinquents" has never proved to be a fruitful scientific enterprise, early intervention strategies should identify a broader class of potential beneficiaries, perhaps organized on a neighborhood or community-level in the highest crime areas.

Similarly, the Rochester Youth Development Study reveals that a nexus exists between school alienation and delinquency. These data support renewed investment and experimentation with programs designed to assist students who are falling behind and to prevent dropping out of school. For youths who have already experienced the juvenile justice system, efforts to support their successful re-entry into school are crucial. These goals will become increasing difficult to achieve as public school budgets are strained to meet basic educational objectives. Yet, the extraordinary costs of maintaining youths in correctional facilities (estimated to be $\$ 35,000-\$ 45,000$ annually) indicate that school-based delinquency prevention programs are extremely cost-effective.

The Rochester Study makes a compelling case for earlier intervention in the lives of troubled youngsters. Too often, budget shortfalls have forced youth-serving agencies, including the juvenile court, to engage in triage of prospective clients. The typical result is that both the agencies and the courts decide not to intervene with minor offenders in order to concentrate scarce resources on "the heavy hitters." The authorities appear to overlook many instances of illegality. Then, the justice officials suddenly "lose their patience" and exercise very stringent sanctions. Predictably, this approach has not produced very positive results.

A preferable social control strategy would mobilize appropriate and proportionate sanctions at every public instance of delinquent behavior. The key to this strategy is to make these early interventions as normalized and non-stigmatizing as possible. As Thornberry et al. remind us, societal reactions to delinquency that weaken bonding to families and schools are likely to escalate the trajectory toward 
delinquency. ${ }^{26}$

\section{THE PITTSBURGH YOUTH STUDY}

The final longitudinal study by Loeber and his associates also relies on multiple observations of three samples of youths in the Pittsburgh area. This study employs many of the measures utilized in the Denver and Rochester studies. However, the researchers have also collected data on personality and psychological factors not covered in other cohort studies. In contrast to the previous studies, the Pittsburgh research is less theoretically-driven and offers a more comprehensive, empirical description of delinquent behavior and its correlates.

Loeber et al. identify sets of variables related to the onset, continuance, and desistence of delinquency. They explore these co-variants within three different age cohorts and across time for each cohort. The design of the Pittsburgh study is "textbook" in terms of identifying causal processes.

In their youngest group, aggressive behavior and social withdrawal (as reported by parents) were the strongest correlates of delinquency: Over time, school problems, delinquent peers, and antisocial values are more salient in terms of delinquent behavior. Not surprisingly, factors associated with stopping delinquent behavior included the opposites of those variables listed above.

Unfortunately, Loeber et al. provide only a few general observations about the implications of their research for prevention and control programs. They seem to suggest that prevention programs should be constructed differently based on the age of clients. They highlight school behavior, especially as youths mature. Despite the rich empirical data, the researchers seem only obliquely interested in policy implications. Yet, some of their co-variates demand some sort of policy explanation. For example, the authors repeatedly find that being an "African-American" increases chances of delinquent behavior. Amazingly, the authors offer no interpretation of why this correlation may exist. Granted, Loeber et al. did not set out to build a theory of delinquency. However, their paper comes dangerously close to abstracted empiricism. After all, facts rarely speak for themselves. Unlike the Denver and Rochester studies, the Pittsburgh researchers offer the potential research consumer little guidance with which to wade through the findings. 


\section{Can Delinguency Research Inform Social Policy?}

Judging from the current policy harvest of these three large scale delinquency research projects, the prospects for researchbased delinquency strategies seem modest. While each study employs "textbook" research designs and very complicated analytic techniques, one is tempted to ask a basic question "Where's the Beef?" The novel policy insights gained from these three papers are limited, at best. Perhaps, as the authors explain, we will need to await future data collection to discover genuinely important new data about the etiology of delinquency. Although the authors have labored hard and, perhaps, advanced the scholarly frontiers of criminology, the immediate payoffs to policy makers and practitioners seem obscure.

The Office of Juvenile Justice and Delinquency Prevention, which funded these studies, has asked the researchers to produce a policy-relevant synthesis of their findings. This product will be of much greater utility to the juvenile justice professional than these present papers. I would urge the authors to examine the extensive evaluation literature on delinquency prevention and control programs so that their commentary can build on this legacy of previous research.

I have several other suggestions for researchers concerned about improving prevention programs. First, the range of variables examined in the research must be widened beyond those included in the present studies. The narrowness of potential causal factors in previous delinquency research is a major problem. For instance, the most powerful correlate to delinquency is gender. Male delinquency rates are 3-5 times higher than female rates. Yet, there are few theories or empirical studies that have adequately investigated this most obvious factor. Prevention programs have rarely addressed gender differences in the etiology of delinquency, despite significant evidence that females and males experience very different "pathways to delinquency."27

Other largely unexplored etiological factors include physical and sexual abuse, and alcohol and drug abuse. Studies of serious and chronic juvenile offenders often report extraordinary high rates of these factors in research subjects. ${ }^{28}$ The National Drug War has

27 Chesney-Lynd, Girls, Crime and Women's Place: Toward a Feminist Model of Female Delinquency, 35 Crime \& Deline. 5 (1989).

28 B. Krisberg, J. Austin, P. Litsky \& K. Joe, The Impact of Juvenile Court SancTroNs (1987) (final report of research for OJJDP; available through OJJDP and the National Criminal Justice Reference Service); S. Baird, Development of Risk Prediction Scales for the California Youthful Offender Parole Board (1988) (prepared for 
focused public attention on the nexus between addiction and criminality, but the needed research and program development in this area is still in its infancy.

A key conceptual issue for delinquency research involves the unit of analysis. All the studies in this volume focus on the individual offender. The researchers want to account for behavior patterns in certain individuals-although, in fact, they are really only describing the probabilities associated with particular categorizations of youths. The bulk of the criminological literature is in this tradition.

In contrast, the work of Shaw and McKay in the 1940s focused on social areas of the city. They sought to explain why certain urban areas possessed higher delinquency rates than others. ${ }^{29}$ Shaw and McKay evolved a perspective on youth crime that stressed the importance of social disorganization. This theory was translated into the Chicago Area Project-the nation's first large scale delinquency prevention effort. The Chicago Area Project worked to organize neighborhoods in collective actions to ameliorate criminogenic influences.

More recently, Linsky and Strauss have reported compelling evidence linking regional patterns in crime and illness with other social indicators. They argue that various measures of societal stress are highly correlated with crime rates. ${ }^{30}$ This research points toward balancing the focus on both individuals and social areas. Moreover, an "ecological" approach to delinquency etiology could generate important clues to community or citywide delinquency prevention strategies.

The community-level prevention model being tested by the Eisenhower Foundation is one example of an "ecological" approach to delinquency prevention. The Eisenhower Foundation has experimented with various approaches to youth employment and political empowerment strategies. Evaluative studies of these approaches are still in progress. ${ }^{31}$ Other prevention programs have emphasized organizing neighborhood groups in "target hardening" activities such as "Operation Block Watch." While these latter approaches seem to reduce resident fears about victimization, there appears to

the National Council on Crime and Delinquency; available through the author); Lewis, Violent Juvenile Delinquents, 18 J. Am. ACAD. OF Child Psych. 307 (1979).

29 C. Shaw \& H. McKay, Juvenile Delinquency and Urban Areas (1972).

30 A. Linsky \& M. Strauss, Social Stress in the United States (1986).

31 L. Curtis \& E. Currie, Youth Investment and Community Reconstruction (1990). 
be little direct impact on crime rates. ${ }^{32}$

What is particularly disturbing in the papers contained in this volume is their seeming detachment from the long tradition of sociological theory and research. It is as if the social structure has disappeared-individuals and families exist in a mythical sociological vacuum.

It seems implausible to discuss family problems without sensitivity to economic, cultural, and social forces. "School problems" appear as attributes of individual youths rather than as products, in part, of dysfunctional public educational systems. The three studies devote virtually no attention to the juvenile justice and child welfare systems. Do we not know something about how inappropriate societal reactions to social problems often exacerbate those problems?

As C. Wright Mills reminded us thirty years ago, the true promise of sociology to improve society can only occur when the "personal troubles of individuals" are translated into "problems of social structure."

The present studies also seem mired in one-dimensional measurement tools, and the analyses are devoid of context. For example, annual administrations of "paper and pencil tests" are not the same as studying real life child developmental processes. To capture adequately this reality, other data sources are necessary. At a minimum, the researchers ought to supplement their quantitative data with field observations in schools and with families, content analyses of youth, and parent's own explanations of motivations and behavior, and "street corner" research to capture neighborhood and community contexts.

\section{Concluding Observations}

Delinquency prevention and control programs in the United States have rarely been grounded in sound empirical data. In part, the absence of rigorous research has led to the failure of most programs and policies designed to reduce youthful criminality. Critics of these failed approaches have explained the poor results in terms of the ineptitude of government and the intractability of delinquents. Some commentators have placed their faith in commonsense retributive and deterrence strategies, although few of these efforts have produced promising results.

Rising crime rates and the morass of prison and jail crowding has led to renewed political interest in prevention programs. To

32 Skogan, Communities, Crime and Neighborhood Organization, 35 CRImE \& Deline. 437 (1989). 
obtain better results in the future will require, however, better data and more innovative thinking. The three youth studies reported in this volume constitute a modest step forward in that direction. Each study moves beyond the methodological deficiencies of previous research. Given enough time, these research teams may identify important empirical findings to guide future prevention programming.

My main challenge to these authors is to bring the social structure back into to the picture. To forget social structure is to deny an essential element of the human experience. This analytic stance will require additional data collection techniques and broader theoretical frameworks. Such augmentations will, I believe, vastly enhance the policy and practical relevance of the research.

Although Attorney General Thornburgh may care little for sociological theories or "root causes," responsible policymakers and citizens cannot afford such a short-sighted posture. Could one seriously imagine medical science or space technology advancing without sound data and logically derived predictions? Despite the sustained ideological and political assault on social science as applied to délinquency and other social problems, the nation needs thorough and creative sociological thinking now more than ever before. 